\title{
Anastomose mamária-coronária: análise de 2923 casos
}

\author{
Jarbas J. DINKHUYSEN*, Luis Carlos Bento de SOUZA*, Maria Zenaide Soares FICHINO*, Paulo CHAC- \\ CUR $^{\star \star}$, Antoninho Sanfins ARNONI ${ }^{\star}$, Leopoldo S. PIEGAS ${ }^{\star}$, Hélio M. de MAGALHÃES ${ }^{\star}$, Paulo P. PAULISTA*, \\ J. Eduardo M. R. SOUSA*, Adib D. JATENE**
}

DINKHUYSEN, J. J.; SOUZA, L. C. B.; FICHINO, M. Z. S.; CHACCUR, P.; ARNONI, A. S.; PIEGAS, L. S.; MAGALHÃES, H. M.; PAULISTA, P. P.; SOUSA, J. E. M. R.; JATENE, A. D. - Anastomose mamáriacoronária: análise de 293 casos. Rev. Bras. Cir. Cardiovasc., 2(1):7-21, 1987

RESUMO: Foi a partir de 1972 que, no Instituto Dante Pazzanese de Cardiologia, se iniciou o emprego da anastomose mamária-coronária associada, ou não, a pontes de safena, ou a outros procedimentos. Nessa época, apenas a artéria mamária interna esquerda (AMIE) foi usada ( 57 casos) para a revascularização da descendente anterior (DA) ou diagonal. No periodo 1973/1974 (386 casos), já ocorreram as primeiras anastomoses seqüênciais AMIE-DA/DA, assim como a artéria mamária interna direita (AMID) passou a ser empregada para ramos diagonais. Com a finalidade de verificar a evolução tardia desta técnica, sua aplicação foi praticamente interrompida, entre 1975/1982, restringindo-se a apenas 43 casos, nesse período. Entretanto, a partir de 1982 até junho de 1986, ocorreu significativo incremento na sua aplicaçāo (2374 casos), sendo que, desde então, a quase totalidade (93\%) das cirurgias de revascularização do miocárdio tem uma ou mais coronárias tratadas com anastomose mamária-coronária. A combinação mais freqüente é AMIE/DA nos casos de mamária isolada e AMIE/DA e AMID/Mg Cx nos casos de dupla mamária. Contudo, observaram-se, na casuística, as mais variadas combinaçōes (71) e associaçōes, abrangendo, praticamente, todas as artérias coronárias. Analisando-se o pós-operatório imediato de um grupo isolado de 177 pacientes operados em 1984, observou-se que esta técnica não influiu na ocorrência de deiscência parcial, ou total, de esterno, em reoperação por sangramento; todavia, ocorreram, em $25 \%$ dos casos, elevação transitória da cúpula frênica, atelectasia em $17 \%$ e derrame pleural residual em $27,6 \%$, geralmente concomitantes. Em relação à evolução tardia, num grupo de 754 pacientes com mamária e safena e com evolução até 9 anos, em $924(71,8 \%$ dos enxertos reestudados, constataram-se indices de permeabilidade de $91,5 \%$ nas mamárias versus $70,6 \%$ (826) das pontes de safena. Em outro grupo (102 pacientes), com evolução entre 5 a 10 anos, apenas com mamária isolada, em 55 reestudos constataram-se $94,4 \%(50)$ de mamárias permeáveis e $5,6 \%$ (3) de ocluídas. A mortalidade intra-hospitalar, nos 2923 casos, foi de $3,45 \%$.

DESCRITORES: anastomose mamária-coronária.

\section{INTRODUÇĀO}

Foi KOLESSOV ${ }^{18}$, em 1967, quem publicou os primeiros relatos da aplicação da AMI (artéria mamária interna) na revascularização cirúrgica do miocárdio, mas foram os trabalhos cie GREEN et alii ${ }^{14}$, em 1968, que popularizaram e estabeleceram os princípios básicos de sua utilização. Logo a seguir, vários autores ${ }^{13,25,32}$ já demonstravam elevados índices de permeabilidade entre 3 e 24 meses de pós-operatório. Permaneciam, entretanto, dúvidas quanto à adequação do fluxo às necessidades

Trabalho realizado no Instituto Dante Pazzanese de Cardiologia, Sāo Paulo, SP, Brasil.

Apresentado ao 14: Congresso Nacional de Cirurgia Cardiaca. Salvador, BA, 27 e 28 de março, 1987.

- Do Instituto Dante Pazzanese de Cardiologia

*. Do Hospital do Coração da Associaçāo do Sanatório Sírio.

Endereço para separatas: Jarbas Dinkhuysen. Caixa Postal 215. São Paulo, SP. Brasil. 
DINKHUYSEN, J. J.; SOUZA, L. C. B.; FICHINO, M. Z. S.; CHACCUR, P.: ARMONI, A. S.; PIEGAS, L. S.; MAGALHĀES, H. M.: PAULISTA, P. P.: SOUZA, J. E. M. R.; JATENE, A. D. - Anastomose mamária-coronária: análise de 2923 casos. Rev. Bras. Cir. Cardiovasc., 2(1):7-21, 1987.

miocárdicas, na preparação do pedículo e na anastomose com a artéria coronária ${ }^{10}$.

Com o passar do tempo, apareceram outros trabalhos demonstrando sua aplicabilidade ${ }^{26}$; todavia sua aceitação pelos diversos Serviços foi lenta e progressiva, sendo que ainda permaneciam inquietações quanto aos resultados a longo prazo, o prolongamento do tempo cirúrgico determinado pela dissecção da mamária associado ao maior refinamento técnico de anastomose. Em 1974, apenas $5,7 \%$ de $400^{30}$ dos cirurgiōes americanos empregavam AMI nas cirurgias de revascularização do miocárdio, enquanto, cinco anos mais tarde, $13 \%$ de $677^{31}$ cirurgiōes a empregavam.

Inqüestionavelmente, a veia safena é o enxerto padrão em cirurgia de coronária ${ }^{20}$, dada sua facilidade de obtenção, quantidade suficiente e pela sua maior resistência a manipulação operatória. Entretanto, é mais propensa a obstrução no primeiro ano, devido a tromboses, hiperplasia ${ }^{20} \mathrm{e}$, tardiamente, pela própria aterosclerose ${ }^{5}$. A AMI, por outro lado, requer sua dissecção e preparação do pediculo, o que pode prolongar o tempo cirúrgico, sua quantidade é limitada e exige maiores cuidados técnicos na anastomose. Sua expectativa de permeabilidade a longo prazo é elevada; entretanto, pode vir a se ocluir precocemente, devido a falhas na anastomose, ou a traumas durante a dissecção e mobilização do pedículo'.

Recentes trabalhos ${ }^{6,12,27,29}$ demonstram índices elevados de permeabilidade a longo prazo significativamente superiores aos da veia safena ${ }^{42}$, sugerindo sua aplicação na revascularização do miocárdio, sempre que possível ${ }^{34}$. O maior obstáculo ao uso indiscriminado da $\mathrm{AMI}$ abrangendo maior número de artérias coronárias é seu limitado número e seu reduzido comprimento; todavia, com o uso de ambas as mamárias ${ }^{12,28,45}$ e com anastomoses sequeênciais ${ }^{46}$, pela abordagem dos ramos da artéria circunflexa pela AMID via retroaórtica ${ }^{35}$ e pela aplicação de enxertos livres de artéria mamária $^{6}$, é possível abordar praticamente toda a árvore arterial coronária, proporcionando, assim, melhor expectativa a longo prazo ${ }^{43}$.

O presente trabalho tem por finalidade demonstrar a evolução técnica que este método apresentou, ao longo do período entre 1972 e 1986 , os aspectos técnicos, complicações relativas ao método no pós-operatório imediato e resultados de reestudos a longo prazo.

\section{MATERIAL E MÉTODO}

Esta casuística engloba a experiência do Instituto Dante Pazzanese de Cardiologia (IDPC), entre julho de 1972 e junho de 1986 (Figura 1) e incluem todos os pacientes nos quais foram aplicadas uma ou mais anastomoses mamária-coronária, isoladamente, ou com pontes de safena e, eventualmente, tiveram procedimentos associados variados.

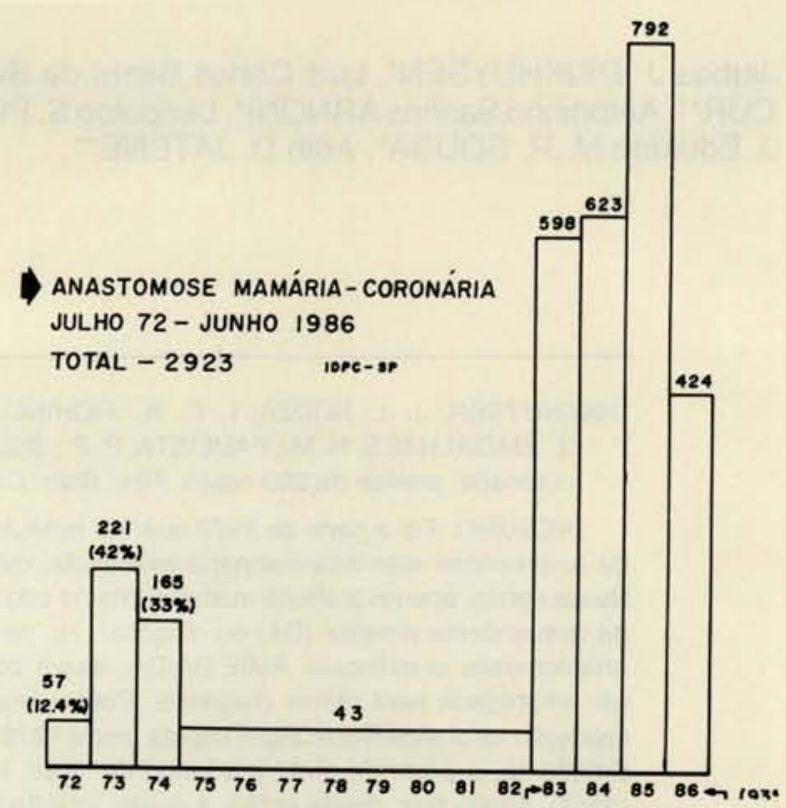

Fig. 1 - Gráfico demonstrando a incidência de anastomose AMI/Coronária durante o periodo compreendido julho/1972 a junho/1986.

Em 1972, apenas a AMIE foi usada em 57 casos, para revascularização da DA ou diagonal isoladamente; em 1973/74, observou-se tendência maior à sua aplicação ( 386 casos) e já com algumas variações técnicas, surgindo as primeiras configurações seqüênciais AMIE-DA/DA, assim como AMID para ramos diagonais. Todavia, entre 1975 e 1982, ocorreu uma quase interrupção no seu emprego (43 casos), que se restringiu, geralmente, a situações especiais de uso obrigatório. A partir de 1982, até a atualidade, sua aplicação se generalizou de tal sorte que $93 \%$ das cirurgias de revascularização do miocárdio têm, necessariamente, uma ou mais artérias tratadas com AMI, nas mais variadas configurações anatômịcas.

Observa-se, na Tabela 1, que a DA foi a que recebeu maior número de anastomoses $(89,5 \%)$, enquanto que a soma entre diagonal, circunflexa e coronária direita abrangeu $10,4 \%$.

Como se vê na Tabela 2, foram utilizadas 2768 mamárias únicas e, na grande maioria, a artéria 
DINKHUYSEN, J. J.: SOUZA, L. C. B.; FICHINO, M. Z. S.; CHACCUR, P.; ARMONI, A. S.; PIEGAS, L. S.; MAGALHĀES, H. M.: PAULISTA, P. P.: SOUZA, J. E. M. R.; JATENE, A. D. - Anastomose mamária-coronária: análise de 2923 casos. Rev. Bras. Cir. Cardiovasc., 2(1):7-21, 1987.

utilizada foi à esquerda $(98,5 \%)$, com 6 configurações anatômicas, incluindo os tipos seqüênciais. A mamária direita foi menos empregada $(1,5 \%)$, principalmente até 1982. Percebe-se, contudo, a abrangência, tanto de mamária esquerda, quanto da direita, sobre toda a árvore coronária. Ocorreram 5 casos de mamária dupla, entre 1973/74, sendo que, em 4 casos, foi acrescentado à mamária um pequeno segmento de safena, com a finalidade de alcançar segmentos mais distais das coronárias. Foram, também, realizadas endarterectomias na descendente anterior ${ }^{13}$, seguidas da anastomose respectiva. Mais recentemente, iniciou-se a confecção de enxertos livres ${ }^{6}$ da AMID.

TABELA 1

DEMONSTRANDO A FREQÜENCIA DA ANASTOMOSE MAMARIA-CORONARIA NA CIRCULAÇÃO CORONÁRIA

$$
\begin{aligned}
& \text { julho/ } 1972 \text { - junho/ } 1986 \\
& \text { ANASTOMOSE AMICORONARIA - (N 3078) }
\end{aligned}
$$

\begin{tabular}{lrr}
\hline descendente anterior & 2756 & $(89,5 \%)$ \\
diagonal & 153 & $(4,9 \%)$ \\
circunflexa (marginal) & 114 & $(3,7 \%)$ \\
coronária direita & 55 & $(1,7 \%)$ \\
\hline
\end{tabular}

O número total de casos foi 155 (Tabela 3), englobando 18 combinações entre ambas as mamárias. As mais freqüentes foram $\mathrm{AMIE} /$ descendente anterior com AMID/marginal da circunflexa passando pelo seio transverso ${ }^{35}(39,3 \%)$, com AMID/coronária direita $(23,8 \%)$ e com AMID/diagonal $(17,4 \%)$. As combinações restantes foram menos freqüentes, ressaltando-se as anastomoses seqüenciais, tanto na mamária esquerda, quanto direita, abrangendo maior número de coronárias. Foram feitas duas endartelectomias prévias à anastomose com a coronária.

\section{TABELA 3}

\begin{tabular}{lr}
\hline MAMARIA DUPLA - CONFIGURACOEES E INCIDENNCIAS \\
\hline $\begin{array}{l}\text { Total de casos } \\
\text { combinaçōes }\end{array}$ & 155 \\
AMIE - DA & 18 \\
AMID - MgCx(r) & $61(39,3 \%)$ \\
AMIE - DA & $37(23,8 \%)$ \\
AMID - CD* & \\
AMIE - DA* & $27(17,4 \%)$ \\
AMID - Dg & \\
AMIE - Cx(mg) \\
AMID - CD \\
AMIE - DA/Dg \\
AMID - MgCx(r) \\
AMIE - DA/Dg \\
AMID - Mg/MgCx(r)
\end{tabular}

* Endarterectomia 2

Foram confeccionadas 3078 (Tabela 4) anastomoses, englobadas as configurações de mamária única e dupla, sendo a AMIE significativamente mais utilizada $(94,1 \%)$. Estão incluídas, nesta tabela, 7 enxertos livres simultâneos da AMID.

Observa-se, na Figura 2, o emprego de ambas as artérias mamárias nos principais ramos da rede coronária, sendo a artéria descendente anterior a que mais anastomoses recebeu $(89,5 \%)$, seguida

TABELA 2

\begin{tabular}{|c|c|c|c|c|c|c|}
\hline CONFIGURAÇĀO & 1972 & $1973 / 74$ & $1975 / 82$ & $1983 / 86$ & & TOTAL \\
\hline $\mathrm{AMIE}-\mathrm{DA}$ & 53 & 358 & $35^{*}$ & $2042^{*}$ & $* *$ & $2488(89,8 \%)$ \\
\hline $\mathrm{AMIE}-\mathrm{Dg}$ & 4 & 16 & 6 & 78 & $*$ & $104(3,7 \%)$ \\
\hline AMIE - Cx(mg) & & 2 & & 15 & $*$ & 17 \\
\hline $\mathrm{AMIE}-\mathrm{CD}$ & & & & 3 & & 3 \\
\hline AMIE - DA/DA & & 3 & & 10 & & 13 \\
\hline $\mathrm{AMIE}-\mathrm{Dg} / \mathrm{DA}$ & & & & 102 & & $102(3,6 \%)$ \\
\hline AMID $-M g C x(r)$ & & & & 12 & & 12 \\
\hline$A M I D-C D$ & & 1 & & 14 & & 15 \\
\hline AMID - Dg & & & & 4 & & 4 \\
\hline \multirow[t]{2}{*}{ AMID - DA } & & 3 & & 2 & & 5 \\
\hline & 57 & $386^{*}$ & 41 & 2285 & $(93 \%)$ & $2768(94,6 \%)$ \\
\hline
\end{tabular}

CONFIGURAÇÓES DA MAMARIA ÚNICA E SUA INCIDÊNCIA NO PERIODO JULHO/1972 A JUNHO/1986

\footnotetext{
- 1973/74 AMIE - Dg MIE + Saf - RAVCX AMID - DA (4) - MID - CD (1)

- 1975/82 AMIE + Saf - DA (3)

- 1983/86 endarterec. DA (14)

** enxerto livre (6)
} 
DINKHUYSEN, J. J.: SOUZA, L. C. B.: FICHINO. M. Z. S.: CHACCUR, P.: ARMONI, A. S.: PIEGAS. L. S.: MAGALHĀES. H M.: PAULISTA. P. P.; SOUZA. J. E. M. R.; JATENE, A. D. - Anastomose mamaria-coronaria: analise de 2923 casos. Rev Bras. Cir. Cardiovasc., 2(1):7-21, 1987.

TABELA 4

NÚMERO TOTAL DE ANASTOMOSES COMA AMIE EA AMID

\begin{tabular}{ccc}
\hline NUMMERO DE ANASTOMOSES & AMICORONARIA \\
\hline Número total de anastomoses & 3078 \\
AMIE & 2897 & $(94,1 \%)$ \\
AMID & $181^{*}$ & $(5,8 \%)$ \\
\hline
\end{tabular}

- Enxerto livre 7

pela diagonal $(4,96 \%)$, marginal da circunflexa $(3,7 \%)$ e coronária direita $(1,78 \%)$.

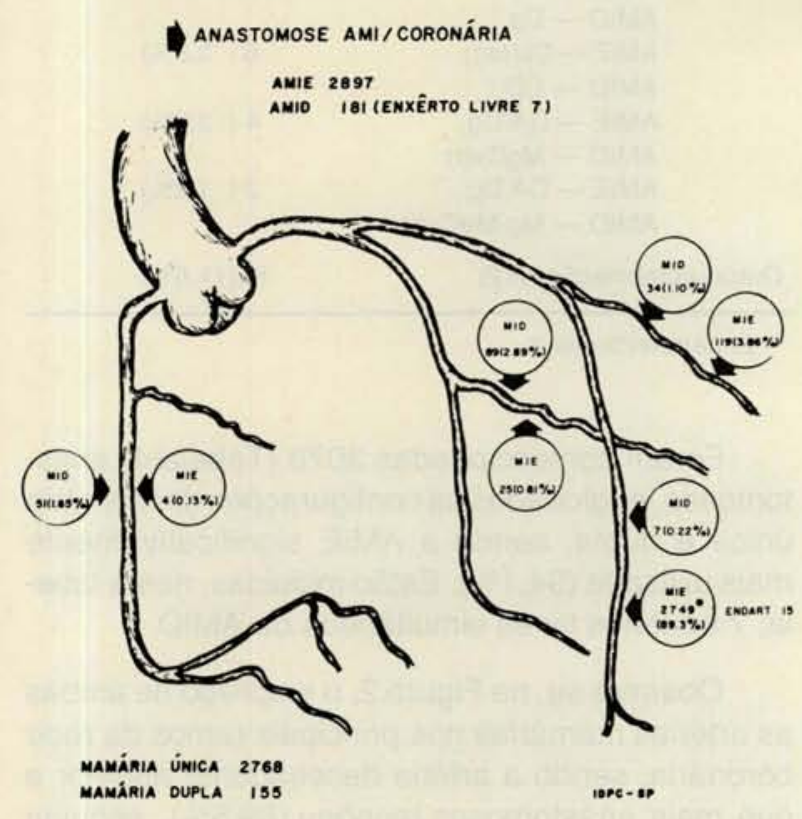

Fig. 2 - Esquema demonstrando a incidência de anastomoses AMI/coronária nas artérias coronárias.

\section{Técnica cirúrgica anastomose AMI/coronária}

\section{Dissecção e preparo do pedículo}

Após a secção do esterno, o pericárdio foi aberto, procedendo-se ao exame das artérias coronárias candidatas à revascularização, pois nem sempre coincidem os detalhes anatômicos das artérias com as informações fornecidas pela cinecoronariografia. Por este motivo, esta medida cautelar é importante, evitando-se dissecções das mamárias desnecessariamente.

Decidida a aplicação de uma ou duas mamárias, o espaço subesternal é exposto com o próprio afastador da toracotomia, descolando-se a gordura pré-mediastinal da fascia endotorácica em direção aos polos proximal e distal do pedículo. Na grande maioria, esta manobra, invariavelmente, provoca a abertura da pleura, acontecendo o mesmo quando o pedículo se localiza na transição da pleura mediastinal com a parietal, ou mesmo em situação intrapleural. Nos casos ce reoperação para uma segunda revascularização miocárdica, a seqüência cirúrgica é a mesma, podendo ocorrer alguma dificuldade de visualizar, ou mesmo palpar o pedículo in situ. Isto geralmente ocorre devido a apreensão da mamária pelos fios de aço passados por ocasião da primeira cirurgia.

A seguir, o pedículo é dissecado com o uso de bisturi elétrico e de uma pinça tipo baioneta específica para este fim (Figura 3 ) e que proporciona acesso fácil à região subesternal.

Durante a dissecção, procura-se deixar uma margem de fascia endotorácica com tecido muscular e gordura de mais ou menos $5 \mathrm{~mm}$ de cada lado da mamária, nas quais geralmente se situam as veias mamárias (Figura 4).

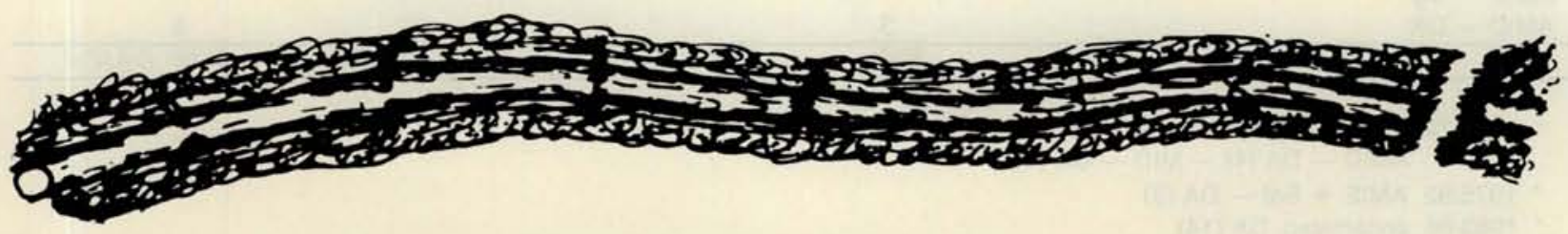

Fig. 4 - Esquema do pedículo já dissecado da artéria mamária com uma margem de $\pm 5 \mathrm{~mm}$ de cada lado. 
Esta margem é necessária tendo em vista possíveis danos na artéria causados pela própria manipulação cirúrgica e pelo calor desprendido do bisturi elétrico, além de serem mantidos os tecidos subjacentes que, eventualmente, podem desempenhar papel importante na conservação deste vaso fora do seu leito natural. A dissecção do polo distal geralmente se prolonga até ao nível da projeção do diafragma, enquanto que, no polo proximal, até as imediações de sua origem na subclávia. $O$ isolamento proximal do pedículo mamário requer alguns cuidados importantes, como a secção dos ramos intercostais, evitando, assim, eventuais quadros de insuficiência mamária-coronária determinados por roubo de sangue ${ }^{41}$. Em segundo lugar, por ser esta região onde passa o nervo frênico, situando-se inferior e medialmente em relação à origem da mamária (Figura 5).

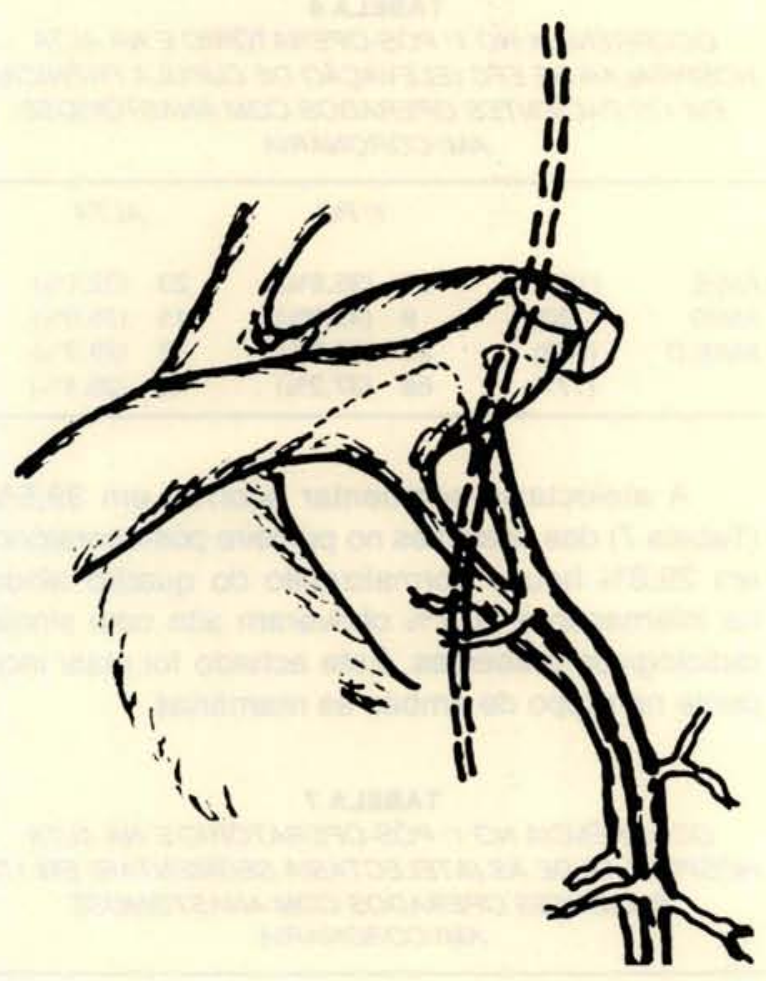

Por isto, a dissecção com bisturi elétrico, a este nível, deve ser cuidadosa, pois, pelo calor desprendido, é possível a ocorrência de algum trauma transitório ou permanente ao frênico, com conseqüente disfunção da hemicúpula diafragmática respectiva, ou mesmo de ambas, no caso de dupla mamária.

Após a liberação completa do pedículo, é feita palpação do mesmo para avaliar o pulso arterial que, invariavelmente, deverá estar presente, pois, caso contrário, é possível a ocorrência de algum dano à mamária, o que impediria sua aplicação. A seguir, o pedículo é envolvido com uma gase úmida em solução diluída de papaverina ou lidocaína, com finalidade de provocar vasodilatação.

\section{Trajeto das mamárias na cavidade pericárdica recortes ou janelas no pericárdio}

Tanto a AMIE quanto a AMID podem revascularizar praticamente todos os ramos coronários, podendo, por isso, ser dirigidas em qualquer direção dentro da cavidade pericárdica. Para tanto, tornam-se necessários recortes ou janelas no pericárdio que permitem a passagem do pedículo evitando angulações, dando maior estabilidade, além de proporcionar maior alongamento, a ponto de se atingirem porções mais distais na coronária. Algumas destas manobras podem determinar aberturas na pleura mediastinal; entretanto, em alguns casos, pode ser possível manter sua integridade.

Se a AMIE for dirigida para a descendente anterior, diagonal e ramos da circunflexa, é feita uma incisão vertical na porção ântero-lateral do hemipericárdio direito até uma distância aproximada de $2 \mathrm{~cm}$ do nervo frênico esquerdo. A AMID dirigindo-se para coronária direita, a incisão é feita no hemipericárdio direito em situação análoga ao esquerdo. Todavia, no caso de ser direcionada aos ramos da parede lateral (diagonalis, marginais de circunflexa), a incisão é feita na projeção do pericárdio sobre a veia cava superior, sempre lembrando que o nervo frênico transita nesta região. Por outro lado, ao invés de cortes, podem ser feitas, com os mesmos cuidados, janelas, com a mesma finalidade.

\section{Técnica operatória}

No IDPC, as cirurgias de coronária são feitas com auxílio de circulação extracorpórea, hipotermia moderada $\left(32^{\circ} \mathrm{C}\right)$ e com pinçamentos aórticos intermitentes relativos a cada anastomose, ou com pinçamento único com cardioplegia e hipotermia sistêmica moderada, não se observando diferenças significativas quanto aos resultados finais. Entretanto, ocorreu, na casuística, algumas operações (quatro) sem auxílio da circulação extracorpórea pela técnica descrita por BUFFOLO ${ }^{2,3}$.

Tanto as anastomoses término-laterais quanto as látero-laterais (seqüenciais) são confeccionadas ou com sutura contínua ou com pontos simples nos ângulos e sutura contínua nas laterais. Ao final, 
DINKHUYSEN, J. J.; SOUZA, L. C. B.; FICHINO, M. Z. S.; CHACCUR, P.; ARMONI, A. S.: PIEGAS. L. S.; MAGALHÄES, H. M.: PAULISTA, P. P.; SOUZA. J. E. M. R.: JATENE, A. D. - Anastomose mamária-coronária: análise de 2923 casos. Rev. Bras. Cir. Cardiovasc., 2(1):7-21, 1987.

o perdículo é fixado ao nível da anastomose e ao longo do enxerto com a finalidade de evitar angulações ou torções após o fechamento do tórax. Um dos aspectos importantes é o eventual estiramento do pedículo com conseqüente torção da sutura mamária-coronária determinado pela compressão do lobo superior do pulmão nas configurações AMIDCD e AMIE-DA e Dg. Por este motivo, o pedículo é posicionado sob o lobo superior, evitando, assim, estiramento do pedículo, principalmente em insuflações pulmonares grandes.

Drenagem pleural: dada a grande abertura de uma ou ambas as pleuras, torna-se necessária a drenagem pleural, pois, caso contrário, formar-seão derrames hepáticos nas bases pulmonares, muitas vezes de difícil resolução, no pós-operatório.

\section{RESULTADOS}

Este item será abordado em duas partes, sendo a primeira relativa a eventos ocorridos no período de pós-operatório imediato e a segunda relativa à análise dos índices de pemeabilidade mamáriacoronária a longo prazo.

\section{Resultados imediatos}

Foram analisados os eventos relacionados diretamente com a técnica no pós-operatório de 619 pacientes operados em 1984, no Hospital do Coração da Associação do Sanatório Sírio, dos quais selecionamos 177 aleatoriamente. Outras complicações deixaram de ser analisadas, tendo em vista sua incidência ser, de um modo geral, idêntica no pós-operatório, tanto de mamária quanto de safena.

O grupo em análise totaliza 177 pacientes, com idade entre 32 e 69 anos $(m=51,3 \pm 8,2$ anos), que apresentou os achados no pré-operatório constantes da Tabela 5.

\section{TABELA 5}

ACHADOS NO PRÉ-OPERATORIO DE 177 PACIENTES SUBMETIDOS A ANASTOMOSE AMIICORONARIA

\author{
177 pacientes $\quad 32-69$ anos \\ Insuficiência cardiaca \\ Doença pulmonar obstrutiva crônica \\ Congestāo venosa \\ Reoperação p/ 2: revascularizaçăo \\ Sinéquias pleurais \\ Bronquiectasias \\ Elevação cúpula frênica
}

$(m=51,3 \% \pm 8,2)$

$10(5,6 \%)$

$8(4,5 \%)$

$8(4,5 \%)$

$3(1,3 \%)$

$2(1,1 \%)$

$1(0,5 \%)$

$1(0,5 \%)$
Analisamos a ocorrência de elevação de cúpula frênica (ECF), atelectasia segmentar (AS) e derrame pleural (DP), geralmente concomitantes, cuja gênese guarda relação direta com a técnica empregada, nas operações nas quais foram aplicadas AMID, AMIE, ou ambas, assim como a incidência de revisões cirúrgicas da hemostasia e eventuais ressuturas da ferida operatória por deiscência.

Observa-se a ECF (Tabela 6) em praticamente $1 / 3$ dos pacientes, sendo que, em $12,2 \%$, ocorreu a normalização ainda na internação e $25 \%$ obtiveram alta ainda com sinais radiológicos de ECF, sendo que este achado foi mais freqüente no grupo de ambas as mamárias $(37,7 \%)$. Cumpre ressaltar que estes achados radiológicos não influíram na evolução habitual dos pacientes e nem provocaram tempo maior de internação.

TABELA 6

OCORRENCIA NO 1:PÓS-OPERATORIO ENA ALTA HOSPITALAR DE EFC (ELEVAÇATO DE CÜPULA FRENICA) EM 177 PACIENTES OPERADOS COM ANASTOMOSE AMICORONARIA

\begin{tabular}{lrrrrr}
\hline & \multicolumn{3}{c}{$1: P O$} & & \multicolumn{1}{l}{ ALTA } \\
AMIE & $(104)$ & 37 & $(35,5 \%)$ & 23 & $(22,1 \%)$ \\
AMID & $(20)$ & 9 & $(45,0 \%)$ & 15 & $(35,0 \%)$ \\
AMIE/D & $(53)$ & 20 & $(37,7 \%)$ & 15 & $(28,3 \%)$ \\
& $(177)$ & 66 & $(37,2 \%)$ & 45 & $(25,4 \%)$ \\
\hline
\end{tabular}

A atelectasia segmentar ocorreu em $39,5 \%$ (Tabela 7) dos pacientes no primeiro pós-operatório, em $28,8 \%$ houve normalização do quadro ainda na internação e $10,7 \%$ obtiveram alta com sinais radiológicos presentes. Este achado foi mais incidente no grupo de ambas as mamárias.

TABELA 7

OCORRENCIA NO 1:PÓS-OPERATÓRIO ENA ALTA HOSPITALAR DE AS (ATELECTASIA SEGMENTAR) EM 177 PACIENTES OPERADOS COM ANASTOMOSE AMICORONARIA

1:PO ALTA

\begin{tabular}{llrlrl} 
AMIE & $(104)$ & 32 & $(30,7 \%)$ & 14 & $(13,4 \%)$ \\
AMID & $(20)$ & 7 & $(35,0 \%)$ & 2 & $(10,0 \%)$ \\
AMIE/D & $(53)$ & 31 & $(58,4 \%)$ & 5 & $(9,4 \%)$ \\
& $(177)$ & 70 & $(39,5 \%)$ & 21 & $(11,8 \%)$ \\
\hline
\end{tabular}

O derrame pleural ocorreu em quase $30 \%$ dos pacientes no 1: pós-operatório (Tabela 8); em $12,4 \%$ ocorreu normalização radiológica do derrame e $17,5 \%$ obtiveram alta hospitalar ainda com sinais de DP pequeno em fase de reabsorção. 
DINKHUYSEN, J. J.; SOUZA, L. C. B.; FICHINO, M. Z. S.; CHACCUR, P.: ARMONI, A. S.: PIEGAS, L. S.; MAGALHĀES, H. M.: PAULISTA, P. P.; SOUZA, J. E. M. R.; JATENE, A. D. - Anastomose mamária-coronária: análise de 2923 casos. Rev. Bras. Cir. Cardiovasc., 2(1):7-21, 1987.

TABELA 8

OCORRENCIA NO 1:PÓS-OPERATORIO ENA ALTA HOSPITALAR DE DERRAME PLEURAL (DP) PEQUENO EM 177 PACIENTES OPERADOS COM ANASTOMOSE AMICORONARIA

\begin{tabular}{lrrlrl}
\hline & \multicolumn{3}{c}{$1: P O$} & \multicolumn{2}{c}{ ALTA } \\
AMIE & $(104)$ & 30 & $(28,8 \%)$ & 16 & $(15,3 \%)$ \\
AMID & $(20)$ & 7 & $(35,0 \%)$ & 5 & $(25,0 \%)$ \\
AMIE/D & $(53)$ & 16 & $(30,0 \%)$ & 10 & $(18,8 \%)$ \\
& $(177)$ & 53 & $(29,9 \%)$ & 31 & $(17,5 \%)$ \\
\hline
\end{tabular}

No grupo de 619 pacientes foram feitas 16 $(2,5 \%)$ revisões de hemostasia por sangramento excessivo (Tabela 9), sendo que, dentre estas, em apenas $4(0,6 \%)$ a causa determinante do sangramento foi relacionada à artéria mamária. Neste mesmo grupo, ocorreram $3(0,4 \%)$ casos de deiscência da ferida operatória que requereram manipulação cirúrgica, sendo 2 com cultura positiva e 1 negativa.

TABELA 9

INCIDÊNCIA DE REVISÓES POR SANGRAMENTOE DEISCÊNCIA DA FERIDA OPERATÓRIA EM G19 PACIENTES SUBMETIDOS A ANASTOMOSE AMICORONARIA

619 pacientes $\mathrm{AMI} /$ coronária

Revisões por sangramento excessivo

Devido às mamárias

$16(2,5 \%)$

$4(0,6 \%)$

Deiscência ferida operatória

$3(0,4 \%)$

Cultura positiva 2

Cultura negativa 1

A mortalidade intra-hospitalar deste grupo de 2923 pacientes (Tabela 10) que sofreram revascularização do miocárdio com anastomose mamáriacoronária isolada, acompanhados ou não de pontes de safena, podendo ter procedimentos variados associados, foi de $3,45 \%$.

TABELA 10

TABELA DE MORTALIDADE INTRA-HOSPITALAR EM 2923 PACIENTES SUBMETIDOS A REVASCULARIZACAOAO DO MIOCARDIO COM PONTESDE SAFENA, ENTRE 1972 E 1986

\begin{tabular}{lccc}
\hline \multicolumn{3}{c}{ TOTAL DE PACIENTES 2923 } \\
ANO & PACIENTES & OBITOS \\
\hline 1972 (julho) & 57 & 01 & $(1,75 \%)$ \\
1973 & 221 & 12 & $(5,42 \%)$ \\
1974 & 165 & 10 & $(6,06 \%)$ \\
$1975 / 82$ & 43 & 02 & $(4,65 \%)$ \\
1983 & 598 & 10 & $(1,67 \%)$ \\
1984 & 623 & 20 & $(3,21 \%)$ \\
1985 & 792 & 32 & $(4,04 \%)$ \\
1986 (junho) & 424 & 14 & $(3.30 \%)$ \\
\hline \multicolumn{4}{c}{} \\
\hline
\end{tabular}

\section{Resultados tardios}

Pela Tabela 11, observam-se vários grupos de pacientes submetidos a revascularização cirúrgica do miocárdio apenas com pontes de safena, somente com anastomose $\mathrm{AMI} /$ coronária e um grupo misto safena com mamária. Trata-se de reestudos analisados em períodos até 10 anos de evolução, buscando-se observar a permeabilidade dos enxertos empregados. Estes grupos não são estatisticamente comparáveis; entretanto, podem, eventualmente, dar uma idéia a respeito do desempenho destes condutos vasculares, a longo prazo.

Inicialmente, é demonstrado um grupo de 275 pacientes operados entre setembro/1968 a junho/1971, dos quais 123 foram a reestudos, com meses entre 1 a 5,5 a 10 e 10 a 15 anos de evolução, tanto por apresentarem sintomatologia de insuficiência coronária, quanto para controle, estando assintomáticos.

TABELA 11

GRUPO DE 275 PACIENTES OPERADOS ENTRE SET./1968 E JUN./1971 SOMENTE COM PONTES DE SAFENA

\begin{tabular}{c|ccc|ccc}
\hline \multirow{2}{*}{$\begin{array}{c}\text { EVOLUÇĀO } \\
\text { (ANOS) }\end{array}$} & \multicolumn{3}{|c|}{ SINTOMÁTICOS } & \multicolumn{3}{c}{ ASSINTOMÁTICOS } \\
\cline { 2 - 7 } N: PAC. & N: PONTES & OBSTR. & N. PAC. & N: PONTES & OBSTR. \\
\hline MESES & 10 & 18 & $09(50,0 \%)$ & 15 & 31 & $03(9,6 \%)$ \\
1 a 5 & 12 & 28 & $11(39,2 \%)$ & 06 & 11 & - \\
5 a 10 & 29 & 51 & $19(37,2 \%)$ & 32 & 57 & $02(3,5 \%)$ \\
10 a 15 & 11 & 21 & $05(23,8 \%)$ & 08 & 11 & - \\
\hline
\end{tabular}


Observa-se, de um modo geral, uma correlação elevada entre presença de sintomas e oclusão de pontes, sendo que, ao final de 15 anos de evolução, aproximadamente $50 \%$ tiveram sintomas e $37 \%$ das pontes de safena se obstruíram. Tal correlação não se caracteriza nos pacientes sintomáticos, onde apenas $4,5 \%$ das pontes vieram a se obstruir em 15 anos de evolução.

O outro grupo a ser analisado (Tabela 12) consta de 102 pacientes operados entre julho de 1972 e junho de 1975, que apresentavam lesão isolada de descendente anterior e foram revascularizados apenas com anastomose mamária-coronária (AMIE). Deste grupo, 53 pacientes concordaram em se submeter a reestudo após evolução de 5 a 10 anos, encontrando-se $94,4 \%$ das mamárias permeáveis. As indicações do reestudo foram apenas para controle, tendo em vista não apresentarem sintomas.

TABELA 12

GRUPO DE PACIENTES (102) PORTADORES DE LESÃO ISOLADA DE DA QUE FORAM REVASCULARIZADOS COM ANASTOMOSE AMIE-DA ISOLADA

\begin{tabular}{lrr}
\hline anast. mamária-coronária & AMIE-DA & 102 pac. \\
reestudos $(5-10$ anos) & 53 & $(51,9 \%)$ \\
$\quad$ mamárias permeáveis & 50 & $(94,4 \%)$ \\
mamárias ocluídas & 3 & $(5,6 \%)$ \\
\hline
\end{tabular}

O terceiro grupo a ser analisado (Tabela 13) consta de 654 pacientes com 1291 enxertos coronários entre pontes de safena e anastomose mamária-coronária, operados entre janeiro de 1975 e agosto de 1984. Destes, 954 enxertos foram analisados num período de evolução de até 10 anos. A causa do reestudo foi devido à recorrência dos sintomas, e assintomática para controle, observando-se que as mamárias mostraram maior índice de permeabilidade $(91,5 \%)$ que as safenas $(70,6 \%)$.

TABELA 13

GRUPO DE PACIENTES (654 PACIENTES - 1291 ENXERTOS) REESTUDADOS COM 1 A 10 ANOS DE EVOLUÇATO

\begin{tabular}{crcc}
\hline pontes safena + AMl/coronária & 654 pac. & 1291 enxertos \\
reestudos (1 a 10 anos) & $924(71,5 \%)$ & enxertos \\
mamárias permeáveis & $38(91,5 \%)$ & \\
safenas permeáveis & $886(70,6 \%)$ & \\
\hline
\end{tabular}

\section{DISCUSSÃO}

A anastomose mamária-coronária tem mostrado resultados mais consistentes que a ponte de veia safena, na revascularização cirúrgica do miocárdio, principalmente no que se refere à evolução tardia.

Devido à constatação de elevados índices de permeabilidade a longo prazo $^{12}$, significativamente superiores $^{38}$ aos da ponte de safena é que, atualmente, a sua aplicação, sempre que possivel, é tida como obrigatória ${ }^{27}{ }^{34} \mathrm{e}$, quando não empregada, constitui-se no fator de risco mais importante, no prognóstico da necessidade de reintervenção para nova revascularização do miocárdio ${ }^{7}$.

As virtudes da veia safena como enxerto coronário se fundamentam em ser de fácil obtenção em quantidade suficiente, de manuseio fácil e por ofertar fluxo de sangue suficiente de sangue ao músculo cardíaco. Contudo, pode apresentar condições obstrutivas, a curto prazo, devido a hiperplasia da intima ${ }^{21} \mathrm{e}$, tardiamente, por aterosclero$\mathrm{se}^{5}$. Já a artéria mamária, a despeito da obtenção mais elaborada, devido à dissecção do pedículo, do tamanho e quantidade limitados e por exigir maiores cuidados técnicos, vem-se constituindo no enxerto coronário de melhor desempenho, porque, raramente, é sede de aterosclerose ${ }^{15}$ e supre a necessidade de perfusão miocárdica ${ }^{21}$, mesmo em situações de alto consumo, não havendo, portanto, contra-indicações gerais ao seu uso ${ }^{30}$.

Desde os primeiros trabalhos publicados ${ }^{14}{ }^{19}$, esta técnica vem sofrendo constantes aprimoramentos, traduzidos por indicações mais amplas e pela busca de um espectro cada vez maior de artérias coronárias revascularizáveis pelas mamárias $^{36,45}$.

Este método mostrou, na década de 1970, pequena aceitação, pois apenas ao redor de $5 \%$ dos cirurgiōes americanos o praticavam. Todavia, a partir de 1980, o método se popularizou, sendo aplicado em $90 \%{ }^{6}$ das cirurgias de revascularização do miocárdio, em 1984. No IDPC, não foi diferente; entre 1972 e 1974, foram realizadas as primeiras operações, adquirindo-se experiência inicial com o método; todavia, era mister o conhecimento dos resultados a longo prazo. A partir de 1982 , sua aplicação se generalizou de tal sorte que, desde então, $93 \%$ dos pacientes operados de revascularização do miocárdio têm uma ou mais coronárias tratadas por anastomose $\mathrm{AMI} /$ coronária. A evolução técnica também se processou ao longo deste período. Inicialmente, empregava-se apenas 1 mamária, sendo a grande maioria a configuração AMIE-descendente anterior e, com menor freqüência, a diagonal e mesmo a coronária direita. Ainda nesta época, surgiram as primeiras anastomoses 
seqüênciais para a mesma, ou para artérias diferentes (DA e Dg), e alguns casos de mamária dupla. Foi a partir de 1982 que, além de se incorporar definitivamente à revascularização do miocárdio ${ }^{23}$, surgiram inúmeras variaçōes técnicas ${ }^{44}, 45$ que revigoraram ainda mais sua aplicabilidade ${ }^{35}$, podendo-se concluir que tanto a mamária esquerda quanto a direita possuem condições de praticamente revascularizar os quatro sistemas arteriais coronários: DA, diagonais, circunflexa e coronária e direita.

Mais recentemente, surgiram, no IDPC, os enxertos livres de mamária ${ }^{12,17,36}$, geralmente obtidos a partir da mamária direita com propriedades hemodinâmicas idênticas à mamária in situ, podendo alcançar porções mais distais da coronária, mas apresentando relativo grau de dificuldade na anastomose proximal na aorta.

Os trabalhos de SAUVAGE et alii ${ }^{37}$ e RANKIN et alii $^{36}$ ilustram as tendências atuais na revascularização completa do miocárdio com uso apenas das mamárias, configurando-se o emprego de mamária bilateral com anastomoses seqüenciais e enxertos livres (enxertos complexos de mamária).

A técnica cirúrgica empregada tem sido a obtenção (dissecção) do pedículo mamário com bisturi elétrico, mantendo-se margem de tecido onde, geralmente, estão as veias mamárias. Além de proporcionar boa margem para manipulação cirúrgica, tem condições de evitar danos à mamária por trauma direto, ou por calor desprendido pelo bisturi elétrico. Por outro lado, julgamos importante a manutenção dos tecidos próprios do pedículo, no sentido de promover eventuais melhores condições de conservação do mesmo, após a anastomose com a coronária. Contudo, HUDDLESTON et alii ${ }^{16}$ demonstraram que o fato de desnudar completamente a mamária, ou retirar apenas a fascia endotorácica, ou, ainda, manter todos os componentes do pedículo, não provocou diferença significativa na permeabilidade destes enxertos, ao final de 10 anos. Entretanto, deve ser considerado que o isolamento completo da mamária retira os vasos linfáticos e veias que a acompanham, assim como dissecar o pedículo próximo à artéria tem o inconveniente de provocar eventuais traumas, pela proximidade da manipulação. Já o pedículo completo tem a desvantagem de esconder hematomas intramurais, ou algum outro trauma na artéria.

Outro aspecto importante é a necessidade de secção de todas as intercostais originárias do pedículo mamário, principalmente as proximais ${ }^{41}$. 0 ramo látero-costal nasce próximo à primeira costela, em $12 \%$ dos individuos ${ }^{19}$, e varia em tamanho e distribuição, podendo ser rudimentar, ou calibroso e extenso, dando origem a vários ramos intercostais ${ }^{40}$. Se esta colateral permanecer aberta na mamária, se estabelecem condiçōes de roubo de fluxo ${ }^{24}$ para o conduto mamária-coronária. Contudo, estas manobras devem ser cuidadosas, pois, na origem do pedículo mamário, estão situados, superiormente, a junção da veia jugular interna com a inominada, inferior e medialmente ao nervo frênico. Ferimentos venosos a este nível muitas vezes são de difícil correção e lesōes sobre o frênico podem determinar paresias transitórias, ou permanentes, do hemidiafragma respectivo, ou mesmo de ambos, nas dissecções bilaterais das mamárias.

A origem das mamárias é extrapericárdica junto à artéria subclávia e, para que possa ser anastomosada a uma coronária, torna-se necessária sua passagem pelo pericárdio. Isto é obtido por meio de recortes, ou janelas, feitos no pericárdio, permitindo, assim, anastomose com porções mais calibrosas da mamária nos casos em que a abordagem da coronária é proximal e maior comprimento quando o local da anastomose é mais distal. Cria-se uma canaleta que servirá de leito ao pedículo, numa condição anatômica estável, evitando possíveis angulaçōes, torções ou estiramento, que podem ocorrer após o fechamento do tórax e se constituir em causas potencialmente obstrutivas. Entretanto, estas aberturas devem ser confeccionadas tendo-se em mente as relações anatômicas que o pericárdio guarda com o nervo frênico.

A anastomose da mamária com a coronária não difere substancialmente, quando se usa veia safena. O calibre do vaso é menor, as paredes mais delgadas e friáveis requerendo maiores cuidados técnicos, a ponto de inúmeros cirurgiões usarem lupa na confecção das anastomoses. Quando se praticam anastomoses látero-laterais nas pontes seqüenciais com veia safena ${ }^{9}$, é possivel uma distribuição harmônica do enxerto sobre as coronárias, visto ser possível realizar anastomoses látero-laterais sem haver a coincidência dos eixos dos dois vasos. Isto é possível porque a safena, pelo seu calibre maior, faz com que a anastomose com a coronária seja feita num orifício não superior a 1/3 do seu diâmetro, não ocorrendo, porisso, eventuais constriçōes da ponte seqüêncial, a este nível.

Já a mamária não possui esta versatilidade, devido a seu calibre geralmente não ser superior a $2 \mathrm{~mm}$, determinando que a anastomose láterolateral necessariamente seja feita na direção do eixo maior dos vasos, para que não ocorram constricções ou angulações na anastomose. Este aspecto 
DINKHUYSEN, J. J.: SOUZA, L. C. B.; FICHINO, M. Z. S.; CHACCUR, P.: ARMONI, A. S.; PIEGAS, L. S.; MAGALHÃES, H. M.; PAULISTA, P. P.; SOUZA, J. E. M. R.; JATENE, A. D. - Anastomose mamária-coronária: análise de 2923 casos. Rev. Bras. Cir. Cardiovasc., 2(1):7-21, 1987

muitas vezes impede a aplicação mais freqüente das mamárias seqüênciais. Contudo, apesar disto, já se observam fortes tendências na confecção de anastomoses seqüênciais ${ }^{16}, 17,36,37, \mathrm{com}$ a finalidade de se obter revascularização completa do miocárdio apenas com as mamárias.

A elevação da cúpula frênica (ECF) é um achado relativamente freqüente, quando se emprega mamária na revascularização miocárdica. GALBUT et alii ${ }^{12}$ relatam a ocorrência deste fenômeno em $4,4 \%$ dos pacientes, nos quais foi empregada mamária dupla, sendo que, em $1,3 \%$, houve necessidade de traqueostomia. Em nosso material (177 pacientes), não ocorreram casos nos quais houvesse necessidade de prolongar o tempo de assistência mecânica ventilatória no pós-operatório imediato, ou mesmo algum outro procedimento mais importante, a despeito de significativa porcentagem de ECF encontrada nos controles radiológicos do pós-operatório imediato, assim como não se prolongou o tempo de internação destes pacientes.

Um dos fatores que, potencialmente, pode aumentar a morbidade no pós-operatório da revascularização do miocárdio, quando se empregam uma ou duas mamárias, é a abertura da pleura. Numa comparação feita entre grupos de pacientes que receberam apenas pontes de safena, com outro no qual as mamárias foram empregadas e, por isto, tiveram alta incidência de pleurotomia, BURGESS et alii ${ }^{4}$ concluíram haver diferenças importantes na oxigenação e no shunting pulmonar, após o tempo principal da operação, e GALBUT et alii ${ }^{2}$ relatam a ocorrência de atelectasia segmentar em $15,4 \%$ dos pacientes operados com mamária. Em nossa experiência, ocorreu atelectasia segmentar aproximadamente em $1 / 3$ dos pacientes, nos primeiros momentos do pós-operatório, principalmente àqueles nos quais foram dissecadas ambas as mamárias, ocorrendo uma melhora significativa do achado radiológico, por ocasião da alta hospitalar. Do mesmo modo, a atelectasia segmentar encontrada nestes pacientes não influiu na evolução rotineira intra-hospitalar desses pacientes.

Outro fenômeno decorrente da abertura da pleura e, eventualmente, da dissecção do pedículo mamário é o derrame pleural. A tendência dos resíduos sangüíneos, que ocorre nas primeiras horas de pós-operatório, é se localizarem no espaço pleural, provocando pequenas coleções. Apesar da colocação de drenagem pleural, encontramos derrames pequenos que também nāo influenciaram na evolução desses pacientes.

A presença de inúmeros ramos colaterais e a área cruenta resultante da dissecção do pedí- culo constituem potenciais pontos hemorrágicos, que, se não sofrerem detalhada hemostasia, poderão determinar, no pós-operatório imediato, quadros de sangramento excessivo requerendo reintervenção. Entretanto, a incidência foi ao redor de $2,5 \%{ }^{12}$.

Outro fator de morbidade decorrente deste método seria a deiscência da ferida operatória, com ou sem infecção, devido à supressão de vasculatura da parede anterior do tórax decorrente da dissecção do pedículo mamário ${ }^{8}$. A impressão é que este aspecto não influiu na ocorrência deste fenômeno ${ }^{8.33}$, tendo em vista que, em apenas $0,4 \%$ (3/619) do nosso material, ocorreram problemas com a ferida operatória, que requereram revisāo cirúrgica.

A mortalidade imediata na revascularização cirúrgica do miocárdio é baixa e aumenta à medida em que se adicionam procedimentos associados. Entretantos, a adição da mamária não modifica estes valores. GALBUT et alii ${ }^{12}$ demonstram mortalidade ao redor de $4 \%$, na década de 1970 e $1 \%$ nos últimos 4 anos. Em nosso meio, FONTES et alii ${ }^{11}$ relatam 2,1\% em 94 casos com a utilização de ambas as artérias mamárias. A casuística apresentada no presente trabalho representa o grupo de 2923 pacientes que foram submetidos a revascularização do miocárdio, que, invariavelmente, receberam uma ou mais anastomoses $\mathrm{AMI} /$ coronária isolada, ou com pontes de safena, associadas ou não a procedimentos adicionais variados, cuja mortalidade foi de $3,45 \%$, ao longo de 16 anos de experiência.

Em recente publicação de LOOP et $a_{1 / i{ }^{27}}$, na qual são feitas comparações entre grupos de pacientes que foram tratados com anastomose da artéria mamária, com a descendente anterior isolada ou combinada a uma ou mais pontes de safena, com outro grupo no qual foram empregadas apenas pontes de safena, após 10 anos de evolução, constatam-se índices superiores de sobrevida, melhor desempenho da função do ventrículo esquerdo e maior permeabilidade no grupo que recebeu mamária. Diversas publicaçōes ${ }^{12,} 15,22,28,29,39,47,48$ e inúmeras outras ressaltam as virtudes desse enxerto coronário, principalmente quanto à capacidade de se manter permeável por períodos prolongados.

Em nosso material, analisamos, inicialmente, um grupo de pacientes operados apenas com veia safena, com tempo de evolução até 15 anos. Constataram-se índices elevados de obstrução de pontes $(37,9 \%)$, ao longo do período, nos pacientes que apresentaram sintomas de insuficiência coro- 
DINKHUYSEN, J. J.; SOUZA, L. C. B.; FICHINO, M. Z. S.; CHACCUR, P.; ARMONI, A. S.; PIEGAS, L. S.; MAGALHÃES, H. M.: PAULISTA, P. P.: SOUZA, J. E. M. R.; JATENE, A. D. - Anastomose mamária-coronária: análise de 2923 casos. Rev. Bras. Cir. Cardiovasc., 2(1):7-21, 1987.

nária, contrastando com o grupo assintomático, no qual apenas $4,5 \%$ apresentaram obstrução nas pontes, no mesmo período.

Por outro lado, selecionamos outro grupo com pacientes portadores de lesão isolada de descendente anterior, que foi tratado unicamente com anastomose AMIE-DA. Mais da metade dos pacientes concordou com reestudo, pois não havia sintomas. Em um período de até 10 anos de evolução, encontramos $94,4 \%$ de permeabilidade das mamárias.

Esse grupo de mamária única pode ser comparável ao assintomático, tratado somente com ponte de safena, sendo ambos praticamente superponíveis, pois os índices de permeabilidade são idênticos, ao final de 10 anos de evolução.

Finalmente, analisamos um grupo misto com evolução de 1 a 10 anos, em cujos pacientes foram aplicadas, tanto mamária, quanto safena e cuja indicação para reestudo foi, principalmente, o retorno dos sintomas. Foram contrastados 924 enxertos, incluindo mamárias e pontes de safena. Os achados demonstraram permeabilidade em $91,5 \%$ das anastomoses mamária-coronária contra $70,6 \%$ das pontes de safena. Estas porcentagens se superpõem às documentadas pela literatura, onde a anastomose $\mathrm{AMI} /$ coronária leva significativa vantagem sobre a ponte de safena.

As diretrizes que norteiam a revascularização cirúrgica do miocárdio, no IDPC, postulam o emprego obrigatório de anastomose mamária-coronária em qualquer paciente, caso não ocorram contra-indicações formais. Não há limite de idade, mas, em pacientes na sétima década de vida, a aplicação é judiciosa. Operações de emergência também não constituem óbice ao seu uso, visto que a dissecção de um ou de ambos os pedículos, assim como a confecção das anastomoses não prolongam o tempo cirúrgico. Esta técnica é vigorosamente indicada em pacientes até 60 anos de idade, nos quais busca-se uma revascularização mais ampla com as mamárias, e nas reoperações para uma segunda revascularização. Entre os cirurgiōes do Serviço, predomina o conceito de revascularizar maior número de coronárias com as mamárias, através de anastomoses seqüenciais e a aplicação de enxertos livres.

\section{RBCCV}

DINKHUYSEN, J. J.; SOUZA, L. C. B.; FICHINO, M. Z. S.; CHACCUR, P.; Arnoni, A. S.; PIEGAS, L. S.; MAGALHÃES, H. M.; PAULISTA, P. P.; SOUSA, J. E. M. R.; JATENE, A. D. - Mammary-coronary artery anastomosis: analysis of 2923 cases. Rev. Bras. Cir. Cardiovasc., 2(1):7-21, 1987

ABSTRACT: At the Instituto Dante Pazzanese de Cardiollogia, the use of mammary-coronary anastomosis was iniciated in 1972, isolated or with saphenous vein by-pass or other procedure. Initially only left internal mammary artery LAD anastomosis was employed in a few (57) cases. In 1973/1974, the aplication of this technique was intensified-386 cases. The method was practically descontinued between 1975 to 1982 - only 43 cases were performed. Since then, its use increased steadily and the right internal mammary artery has been used as well. In 1984, studying 177 patients, we observed that this technique does not influence the incidence of external dehiscence on the reoperation for bleeding; but in $25 \%$ occurred an elevation of hemolateral diaphragm, in $17 \%$ atelectasis, and in $27.6 \%$ pleural effusion. In 654 patients with mammary-coronary anastomoses and saphenous vein grafts followed up to nine years; patency was $91.5 \%$ for mammaries and $70.6 \%$ for saphenous veins. In another group of 102 patients with isolated mammarycoronary anastomosis patency was $94.4 \%$ in a period between 5 and 10 years. The mortality rate of all 2923 cases was $3.45 \%$.

DESCRIPTORS: mammary-coronary artery anastomosis.

\section{REFERÊNCIAS BIBLIOGRÁFICAS}

1 BARBORIAK, J. J.; PINTAR, K.; KORNS, M. E. - Atherosclerosis in aortocoronary vein grafts. Lancet, 2 (7881): 621-624, 1974.
2 BUfFOlO, E.; ANDRADE, J. C. S.; SUCCI, J. E.; LEĀO, L. E. V.; CUEVA, C.; BRANCO, J. N. R.; GALLUCCI, C. - Revascularização direta do miocárdio sem circulação extracorpórea: descrição da técnica e resultados iniciais. Arq. Bras. Cardiol., 38 (5): 365-373, 1982. 
DINKHUYSEN, J. J.; SOUZA, L. C. B.; FICHINO, M. Z. S.; CHACCUR, P.; ARMONI, A. S.; PIEGAS, L. S.; MAGALHÃES, H. M.: PAULISTA, P. P.: SOUZA, J. E. M. R.; JATENE, A. D. - Anastomose mamária-coronária: análise de 2923 casos. Rev. Bras. Cir. Cardiovasc., 2(1):7-21, 1987

3 BUFFOLO, E.; ANDRADE, J. C. S.; SUCCI, J. E.; LEĀO, L. E. V.; GALLUCCI, C. - Direct myocardial revascularization without cardiopulmonary bypass. Thorac. Cardiovasc. Surg., 33 (1): 26-29, 1985

4 BURGESS III, G. E. ; COOPER Jr., J. R.; MARINO, R. J.; PEULER, M. J.; MILLS, N. L.; OCHSNER, J. L. - Pulmonary effect of pleurotomy during and after coronary artery bypass with internal mammary artery versus saphenous vein grafts. $J$. Thorac. Cardiovasc. Surg. 76 (2): 230-234, 1978.

5 CAMPEAU, L.; ENJALBERT, M.; LESPÉRANCE, J.; VAISLIC, C.; GRONDIN, C. M.; BOURASSA, M. G. Atherosclerosis and late closure of aortocoronary saphenous vein grafts: sequentional angiografic studies at 2 weeks, 1 year, 5 to 7 years, and 10 to 12 years after surgery. Circulation, 68 (Supl. 2): 1-7, 1983.

6 COSGROVE, D. M.; LOOP, F. D.; LYTTLE, B. W.; GOORMASTIC, M.; STEWART, R. W.; GILL, C. C.; GOLDING, L. R. - Does mammary artery grafting increase surgical risk? Circulation, 72 (Supl. 2): 170-174, 1985.

7 COSGROVE, D. M.; LOOP, F. D.; LYTTLE, B. W.; GILL, C. C.; GOLDING L. A. R.; GIBSON, C.; STEWART, R. W.; TAYLOR, P. C.; GOORMASTIC, M. - Predictors of reoperation after myocardial revascularization. - J. Thorac. Cardiovasc. Surg. 92 (5): 811-821, 1986.

8 CULLIFORD, A. T.; CUNNIGHAM, J. N.; ZEFF, R. H.; ISOM, O. W.; TEIKO, P.; SPENCER, F. C. - Sternal and costochondrial infections following open-heart surgery. J. Thorac. Cardiovasc. Surg., 72 (5): 714-726, 1976.

9 DINKHUYSEN, J. J.; CHACCUR, P.; CONFORTI, C. A.; ABDULMASSIH NETO, C.; ARNONI, A. S.; PAULISTA, P. P.; SOUZA, L. C. B.; JATENE, A. D. - Revascularização cirúrgica do miocárdio com ponte de safena seqüencial. Arq. Bras. Cardiol., 46 (3): 157-164, 1986.

10 FLEMMA, R. J.; SINGHT, H. M.; TECTOR, A. J.; LEPLEV Jr., D.; FRASER, B. L. - Comparative hemodynamic properties of vein and mammary artery in coronary bypass operation. Ann. Thorac. Surg., 20 (6): 619-627. 1975.

11 FONTES, R. D.; RAMIRES, J. A. F.; DALLAN, L. A. O.; OLIVEIRA, S. F.; OLIVEIRA, S. A.; VERGINELLI, G.; PILEGGI, F.; JATENE, A. D. - Revascularizaçāo miocardica com a utilização de ambas as artérias mamárias internas. Rev. Paul. Med., 104 (5): 236-239. 1986.

12 GALBUT, D. L.; TRAAD, E. A.; DORMAN, M. J.; DE WITT, P. L.: LARSEN, P. B.: WEINSTEIN, D.; ALLY, J. M.; GENTSCH, T. O. - Twelve-year experience with bilateral internal mammary artery grafts. Ann. Thorac. Surg., 40 (3): 264-270, 1985. artery anastomosis: three years experience with 165 patients. Ann. Thorac. Surg., 14 (3): 260-271, 1972.
14 GREEN, G. E.; STERTZER, S. H.; REPPERT, E. H. Coronary arterial bypass grafts. Ann Thorac. Surg., 5 (5): 443-450, 1968

15 GRONDIN, C. M.: CAMPEAUL, L.; LESPÉRANCE, J.; ENJALBERT, M.; BOURASSA, M. G. - Comparison of date change in internal mammary artery and saphenous vein grafts in two consecutive series of patients 10 years after operation. Circulation, 70 (Supl. 1): 208-212, 1984

16 HUDDLESTON, C. B.; STONEY, W. S.; ALFORD Jr., W C.: BURRUS, G. R.; GLASSFORD Jr., D. N.: LEA IV, J. W.: PETRACEK, M. R.; THOMAS Jr., C. S. Internal mammary grafts: technical factors influencyal patency. Ann. Thorac. Surg., 42 (5): 543-549, 1986.

17 KAMATH, M. L.; MATYSIK, L. S.; SCHMIDT, D. H.; SMITH, L. L. - Sequencial internal mammary artery grafts: expanded utilization of an ideal conduit. J. Thorac. Cardiovasc. Surg., 89 (2): 163-169, 1986.

18 KOLESSOV, V. I. - Mammary artery - coronary artery anastomosis as a method of treatment for angina pectoris. J. Thorac. Cardiovasc. Surg., 54 (4): 535-544, 1967.

19 KROPP, B. N. \& KINGSTON, O. - The lateral costal branch of the internal mammary artery. J. Thorac. Surg. 21( ): 421-425, 1951.

20 JOHNSON, A. M.; KRON, I. L.; WATSON, M. M.; GIBSON R. S.; NOLAN, S. P. - Evaluation of postoperative flow reserve in internal mammary artery bypass grafts. J. Thorac. Cardiovasc. Surg. 92 (5): 822-826, 1986.

21 JOHNSON, W. D.; AUER, J. E.; TECTOR, A. J. - Late changes in coronary vein grafts. Am. J. Cardiol. 26 (6): 640,1970 . (Resumo).

22 JONES, J. W.; OCHSNER, J. L.; MILLS, N. L.; HUGHES, L. - Clinical comparison between patients with saphenous vein and internal mammary artery as a coronary graft. J. Thorac. Cardiovasc. Surg., 80 (3): 334-341, 1980.

23 LEÃO, L. E. V.; BUFFOLO, E.; ANDRADE, J. C. S.; SUCCI, J. E.; GODOY, M. F.; CARVALHO, A. C. C.; RIBEIRO, E. E.; LAMOUNIER, E. N.; GALLUCCI, C. - Revascularização miocárdica pela anastomose mamário-coronária: análise crítica dos resultados imediatos e tardios. Arq. Bras. Cardiol., 37 (4): 231-236, 1981.

24. LOOP, F. D. - Operative technique in myocardial revascularization. Surg. Clin. North. Am., 55(5):1181-1191, 1975

25 LOOP, F. D.; EFFLER, D. B.; SPAMPINATO, N.; GROVES, L. K.; CHEANVECHAI, C. - Myocardial revascularization by internal mammary artery grafts. $J$. Thorac. Cardiovasc. Surg., 63 (4): 674-680, 1972.

26 LOOP, F. D.; IRARRAZAVAL, M. F.; BREDEE, J. J.; SIEGEL, W.; TAYLOR, A. C.; SHELDON, W. C. - Internal mammary artery graft for ischemic heart disease: effect of revascularization on clinical status and survival. Am. J. Cardiol., 39 (4): 516-522, 1977. 
DINKHUYSEN, J. J.; SOUZA, L. C. B.; FICHINO, M. Z. S.; CHACCUR, P.; ARMONI, A. S.: PIEGAS. L. S.: MAGALHĀES, H. M.; PAULISTA, P. P.; SOUZA, J. E. M. R.; JATENE, A. D. - Anastomose mamária-coronária: análise de 2923 casos. Rev. Bras. Cir. Cardiovasc., 2(1):7-21, 1987. WART, R. W.; GOORMASTIC, M.; WILLIAM, G. W.; GOLDING, L. A. R.; GIL, C. C.: TAYLOR, P. C.; SHELDON, W. C.; PROUDFIT, W. L. - Influence of the internal-mammary-artery grafts on 10-year survival and other cardiac events. N. Engl. J. Med., 314 (1): 1-6, 1986.

28 LYTTLE, B. W.; COSGROVE, D. M.; SALTUS, G. L. TAYLOR, P. C.; LOOP, F. D. - Multivessel coronary; revascularization without saphenous vein: long term results of bilateral internal mammary artery grafting. Ann. Thorac. Surg., 36 (5): 540-547, 1983.

29 LYTTLE, B. W.; LOOP, F. D.; COSGROVE, D. M.; RA. TLIFF, N. B.; EASLEY, K.; TAYLOR, P. C. - Long-term ( 5 to 12 years) serial studies of internal mammary and saphenous vein coronary bypass grafts. J. Thorac. Cardiovasc. Surg., 89 (3): 248-258, 1985.

MILLER Jr, D. W.; HESSEL II, E. A.; WINTERSHEID, L. C.; MERENDINO, K. A.; DILLARD, D. H. - Current practice of coronary bypass surgery: results of a national survey. J. Thorac. Cardiovasc. Surg., 73 (1): 75-83, 1977.

31 MILLER Jr., D. W.; IVEY, T. D.; BAILEY, W. W.; JOHNSON, D. D.; HESSEL, E. H. - The practice of coronary artery bypass in 1980 . J. Thorac. Cardiovasc., 81 (3): 423-427, 1981.

MILLS, N. W. \& OCHSNER, J. L. - Technique of internal mammary-to-coronary artery bypass. Ann. Thorac. Surg., 17 (3): 237-246, 1974.

33 NKONGHO, A.; LUBER, J. M.; BELL-THOMPSON, J.; GREEN, G. E. - Sternotomy infection after harvesting of the internal mammary artery. J. Thorac. Cardiovasc. Surg., 88 (5 Pt1): 788-789, 1984.

OKIES, J. E.; PAGE, V. S.; BIGELOW, J. C.; KRAUSE, A. H.; SALOMON, N. W. - The left internal mammary artery: the graft of choice. Circulation, 70 (Supl. 1): 213-221, 1984

35 PUIG, L. B.; FRANCCA NETO, L. F.; RATI, M.; RAMIRES, J. A. F.; LUZ, P. L. PILEGGI, F.; JATENE, A. D. A technique of anastomosis of the right internal mammary artery to the circumflex artery and its branches. Ann. Thorac. Surg., 38 (5): 533-534, 1984.

RANKIN, J. S.; NEWMAN, G. E.; BASHORE, T. M.; MUHLBAIER, L. H.; TYSON, G. S.; FERGUSON Jr., T. B.; REVES, J. G.; SABISTON, D. C. - Clinical and angiographic assessment of complex mammary artery bypass grafting. J. Thorac. Cardiovasc. Surg., 92 (5): 832-846, 1986.

37 SAUVAGE, L. R.; WU, H. D.; KOWALSKY, T. E.; DAVIS, C. C.; SMITH, J. C.; RITTENHOUSE, E. A.; HALL, D. G.; MANSFIELD, P. B.; MATHISEN, S. R.; USUI, Y.; GOFF, S. G. - Healing basis surgical techniques for complete revascularization on the left ventricle using only the internal mammary arteries. Ann. Thorac. Surg., 42 (4): 449-465, 1986.
38 SCHMIDT, D. H.; BLAU, F.; HELLMAN, G.; GRZELAK, L.; JOHNSON, W. D. - Isoproterenol-induces flow responses in mammary and vein bypass grafts. J. Thorac. Cardiovasc. Surg., 80 (3): 319-326, 1980.

39 SIEGEL, W. \& LOOP, F. D. - Comparison of internal mammary artery and saphenous vein bypass grafts for myocardial revascularization. Circulation. 54 (1): 1-3, 1976.

$40 \mathrm{SINGH}, \mathrm{R} . \mathrm{N}$. - Internal mammarv arteriography: a new catheter technique by right brachial approach. Cathet Cardiovasc. Diagn., 6 ( ): 439-449, 1980.

41 SINGH, R. N. \& SOSA, J. A. - Internal mammary arterycoronary artery anastomosis: influence of the side hranches on surgical result. J. Thorac. Cardiovasc. Surg., 82 (6): 909-914, 1981.

42 SINGH, R. N.; SOSA, J. A.; GREEN, G. E. - Long-term fate of the internal mammary artery and saphenous vein grafts. J. Thorac. Cardiovasc. Surg., 86 (3): 359-363, 1983.

SPENCER, F. C. - The internal mammary artery: the ideal coronary bypass graft? N. Engl. J. Med., 314 (1): 50-51, 1986.

44 TECTOR, A. J. \& SCHMAHL, T. M. - Technique for multiple internal mammary artery bypass grafts. Ann. Thorac. Surg., 38 (3): 281-286, 1984.

45 TECTOR, A. J.; SCHMAHL, T. M.; CANINO, V. R. - Expanding the use of the internal mammary to improve patency in coronary artery bypass grafting. J. Thorac. Cardiovasc. Surg., 91 (1): 9-16, 1986.

46 TECTOR, A. J.; SCHMAHL, T. M.; CANINO, V. R.; KALLIES, J. R.; SANFILIPPO, D. - The role of sequencial internal mammary artery graft in coronary surgery. Circulation, 70 (Supl. 1): 222-225, 1984.

47 TECTOR, A. J.; SCHMAHL, T. M.; JANSEN, B.; KALLIES, J. R.; JOHNSON, G. - The internal mammary artery graft: its longevite after coronary bypass. Jama, 246 (09): 2181-2183, 1981

48 TYRAS, D. H.; BARNER, H. B.; KAISER, G. C.; CODD, J. E.; PENNINGTON, D. G.; WILLMAN, V. L. - Bypass grafts to the left anterior descending coronary artery J. Thorac. Cardiovasc. Surg., 80 (3): 327-333, 1980

\section{Discussão}

DR. ÊNIO BUFFOLO

São Paulo, SP

Gostaríamos, inicialmente, de cumprimentar os autores pela excelência do estudo, expressividade de casuística e oportunidade da discussão do tema. Como pudemos observar na apresentação, após um entusiasmo inicial com o emprego da artéria mamária, ao final dos anos 70 e início 
dos anos 80 , ocorreu uma diminuição expressiva do seu uso, a favor dos enxertos de veia safena. Aliás, é oportuno lembrar que o grupo do Dr. Jarbas, repetindo o trabalho de Flemma e colaboradores, demonstrou, originalmente, em nosso meio, que os fluxos através das veias safena eram superiores, em relação aos da artéria mamária. Esta constatação, aliada à indiscutível dificuldade técnica da dissecção do pedículo mamário, fez, na época, com que se relegasse a um segundo plano a opção da mamária. (Slide) Nos últimos anos, com a constatação da superioridade, a longo prazo, das mamárias, em relação às safenas, ocorreu um sensível incremento no seu uso. O slide procura demonstrar, graficamente, a evolução do emprego da mamária ao longo dos anos e que, em linhas gerais, se superpõe à do trabalho apresentado. Os resultados obtidos pelos autores são elogiáveis, especialmente no que diz respeito à baixa mortalidade e bons índices de permeabilidade, sendo superponiveis aos melhores resultados cirúrgicos da América do Norte. Cumpre ressaltar que, apesar do cuidado referido pelo $\mathrm{Dr}$. Jarbas, $1 / 4$ dos pacientes com mamária esquerda receberam alta hospitalar com paresia de cúpula esquerda e, no caso da utilização da mamária direita, $1 / 3$ dos casos tiveram esta complicação. Os aspectos técnicos envolvendo a dissecção da mamária e a técnica operatória constituem ponto de destaque do trabalho. (Slide) Salientamos que é de muita importância o isolamento total da mamária de seu estojo periesternal até o primeiro ramo intercostal, uma vez que sua permanência pode determinar importante roubo de fluxo, conforme o diapositivo ilustra. Ainda, se a dissecção da mamária, em sua porção proximal, for realizada com bisturi elétrico, pode determinar lesão temporária ou definitiva dos frênicos. Nesta região, separamos a mamária do tecido adventicial frouxo por dissecção romba. Finalmente, gostaríamos de ressaltar um aspecto que não foi discutido no trabalho e tampouco na literatura, que julgamos de extraordinária importância. A artéria mamária utilizada como reguladora do fluxo coronário é uma artéria sistêmica muito sujeita a variações de fluxo decorrentes das respostas humorais e da volemia. Assim, hipotensōes por hipovolemia ou vasocontrição por dor, hipotermia, ou mau débito, podem determinar cessação do fluxo pela mamária, com isquemia miocárdica conseqüente. Já constatamos, em nossa experiência, pacientes nos quais aparece corrente de lesão no território revascularizado e a exploração cirúrgica imediata demonstra a permeabilidade da anastomose associada a espasmo segmentar da mamária, reversível com aquecimento, vasodilatadores e reposição volêmica. Este tipo de comportamento especial de uma artéria sistêmica não ocorre com as veias safenas, que são desprovidas de mecanismos indutores de espasmos. Terminando meus comentários, diria que a casuística e os resultados aqui apresentados são dignos dos maiores elogios e representam, de maneira otimizada, os resultados verificados em nosso meio. Merece menção especial o cuidado da redação e o zelo na procura de trabalhos correlatos da literatura nacional, o que, infelizmente, não tem sido observado, em nosso meio. A redação do trabalho e a leitura da experiência nacional corrigem, salutarmente, esta distorção.

\section{DR. LUIZ BORO PUIG}

Sâo Paulo, SP

Em 1985, enviamos um questionário às nossas equipes de cirurgia cardiaca, contendo perguntas sobre o emprego de artéria mamária interna na revascularização direta do miocárdio, e recebemos 22 respostas.

Até 1980 apenas, 23\% das equipes usavam artéria mamária na revascularização direta do miocárdio. Em 1985, esta porcentagem passou a $91 \%$, assim distribuídas: $3(14 \%)$ das equipes em até $10 \%$ dos seus pacientes; $5(23 \%)$ de 11 a $30 \%$; $6(27 \%)$ de 31 a $50 \% ; 4(18 \%)$ de 51 a $70 \%$ e, em $2(9 \%)$ equipes, em mais de $71 \%$ dos pacientes. Quanto às complicações pós-operatórias, $82 \%$ das equipes responderam que não eram maiores com o emprego de artéria mamária. O uso das duas artérias mamárias constitui-se de vantagens e desvantagens, que poderão ser avaliadas à medida que as experiências vão sendo acumuladas. $\mathrm{Na}$ nossa experiência, foram operados 116 pacientes com o emprego das duas artérias mamárias, os quais dividimos em dois grupos: Grupo I (57 pacientes) - artérias mamárias associadas a ponte de veia safena e Grupo II (59 pacientes) - artérias mamárias isoladas. A mortalidade, no Grupo II, foi de $10,5 \%$, sendo $3,5 \%$ de causas cardíacas (fibrilação ventricular e hipopotassemia) e 7,0\% de causas não cardíacas (insuficiência respiratória, acidente vascular cerebral, úlcera perfurada e hemorragia digestiva). Dos 6 casos de óbito, em 4 os pacientes tinham idade superior a 60 anos. As complicações mais freqüentes foram: reoperação por sangramento $5(8,7 \%)$ casos, deiscência de esterno $2(3,5 \%)$, infarto pós-operatório $2(3,5 \%)$ casos e fibrilação ventricular $1(1,7 \%)$ caso. A mortalidade, no Grupo II, foi de 1,6\% (1 caso) - fibrilação ventricular. Neste grupo, nenhum paciente foi reoperado por sangramento. As complicações obser- 
vadas foram: fibrilação ventricular $3(5 \%)$ casos, deiscência de esterno $1(1,6 \%)$ caso e paralisia bilateral do diafragma $1(1,6 \%)$ caso. Baseados nesta experiência, como regra, atualmente consideramos 60 anos de idade como limite para o emprego das duas artérias mamárias, associadas ou não à ponte de veia safena.

\section{DR. DINKHUYSEN}

(Encerrando)

Agradeço o comentário e as palavras gentís do Dr. Ênio Buffolo, acrescentando que, na realidade, os pacientes não apresentaram quadros de disfunção diafragmática a ponto de requererem medidas terapêuticas específicas. A elevação da cúpula frênica foi um achado radiológico freqüente, nos pacientes nos quais foram empregadas uma, ou ambas as mamárias. Este sinal radiológico, eventualmente, também ocorre nos pacientes com pontes de safena. No que se refere à possibilidade de a artéria mamária apresentar eventuais constriç̧ōes tipo es- pasmos, peculiares a um ramo arterial, é um fato incontestável; contudo, o enxerto mamária-coronária pode, também, apresentar angulações, torçōes e distensões, visto que possui dois pontos fixos na sua origem na subclávia e na anastomose com a coronária e entre estas situam-se estruturas móveis, como o pericárdio e o pulmão, que poderiam, por ação mecânica, ocasionar dificuldades de fluxo, principaimente quando não é criado um leito específico para o enxerto. Gostaria de acrescentar que, em nosso Serviço, não temos observado quadros isquêmicos em anastomoses mamária-coronária, no pós-operatório imediato, exceto em um caso (MID-CD), no qual se observou uma constricção envolvendo a anastomose distal e proximidades. $\mathrm{O}$ Dr. Puig mostra sua casuística com emprego desta técnica, demonstrando resultados superponiveis aos apresentados no trabalho. Não poderia deixar de mencionar sua contribuição em descrever a técnica que utiliza a mamária direita, via espaço retroaórtico, revascularizando ramos coronários da parede lateral, a qual faz parte do elenco de variantes técnicas apresentadas neste trabalho. Obrigado. 